\title{
Maintaining Professional Standards in Early Childhood Teacher Preparation: Evaluating Adaptations to Fieldwork-Based Experiences During COVID-19
}

\author{
Larisa Callaway-Cole ${ }^{1}$ (D) Ashley Kimble ${ }^{1}$ (D)
}

Accepted: 9 June 2021 / Published online: 21 June 2021

(C) The Author(s), under exclusive licence to Springer Nature B.V. 2021

\begin{abstract}
At institutions striving to maintain face-to-face field placements and instruction amidst the COVID-19 pandemic, circumstances changed daily in response to new developments at the university, local school districts, and personal circumstances. This mixed-methods study explored and evaluated the adaptations made to early childhood teacher preparation courses in an undergraduate program in order to provide relevant training through a variety of instructional modalities including faceto-face, virtual, hypothetical, and mixed reality. Focused on maintaining professional standards through adapted coursework designed to meet student learning outcomes, instructors reflected on multiple instructional modalities and analysis of demonstrable learning outcomes for students in a four-year bachelor's degree program resulting in state teacher certification. Data were collected from students from three different cohorts $(n=26)$ through course assignments, reflections, and instructor- and self-assessments. Results highlight several areas where students found success in meeting professional standards in new ways including: knowledge of development, relevant and responsive curriculum, collaborative engagement, cultural and familial knowledge, inclusive and individualized design, and flexibility and adaptability. Students were prepared to teach in the following ways: designing curriculum, implementation, and reflective practice. Students felt unprepared to teach citing needing more practice and continued skills development. These findings highlight the need for flexibility in the face of the pandemic and underscore the importance of using the new knowledge and practices generated about student learning to reinvent early childhood teacher education programs when faced with post-pandemic realities.
\end{abstract}

Keywords COVID-19 · Early childhood teacher preparation · Field experiences · Student learning · Preservice teachers · Reflective practice

\section{Introduction}

Due to the COVID-19 pandemic, field experiences in early childhood teacher preparation programs are rapidly shifting. Just as early childhood educators faced significant changes teaching young children (Szente, 2020), faculty in teacher preparation programs must make changes and adjustments to continue preparing preservice early childhood educators amidst the pandemic (Quezada et al., 2020). Early childhood care and education (ECEC) is essential to children and

Larisa Callaway-Cole

larisa.callaway-cole@okstate.edu

1 Human Development and Family Science, Oklahoma State University, 233 Nancy Randolph Davis, Stillwater, OK 74078, USA families during the pandemic (Murray, 2020). These new experiences, whether they be virtual with tiny faces in boxes on a computer screen (Swadener et al., 2020) or socially distanced classrooms (Levinson et al., 2020), require new approaches to teaching and learning. Online teaching and learning practices have been significantly developed over the last 20 years (Carrillo \& Flores, 2020), with major emphasis on pedagogical approaches that increase student engagement and humanize the online classroom (Pacansky-Brock et al., 2020).

In this article, we describe student and instructor assessments of student learning through a variety of fieldworkbased experiences designed and adapted to meet the needs of preservice teachers during COVID-19 in a 4-year teacher certification program that results in teacher certification from the state. Field placements ranged from face-to-face, virtual, hypothetical, and mixed reality, which will be defined later. 
Each experience engaged students in constructing knowledge of pedagogical practices through planning, implementation, and reflection.

\section{Review of the Literature on Alternative Instructional Approaches}

In response to the COVID-19 pandemic, we rapidly made significant changes to transform our coursework, including instructional and field placement modalities. In order to maintain a holistic practice-based approach (Hollins, 2011) to teacher preparation, it was important to provide students with an integrated learning experience reflective of content knowledge, planning, guided practice/implementation, and reflection.

Field placements are a necessary element of teacher preparation programs. Through field placements, students engage in praxis (Moore, 2003), connecting theoretical constructs learned in coursework and then applying that learning through their work with cooperating teachers, children, and families in classroom and community settings. Preservice teachers have the ability to make observations, implement curriculum, and assess children's learning. There is evidence that field placements are most effective when coursework is relevant and well-connected to placements, and when programs emphasize inquiry and reflection on teaching and learning (Capraro et al., 2010). However, amidst the pandemic, nothing about what we are going through is normal. "Best practice" is not always possible when face-toface placements are limited. Professional responsibility to our community dictates that we make adaptations to keep everyone safe, children and teachers included. There is no version of a face-to-face field placement absent of risk right now (Dibner et al., 2020). Thus, it is necessary to compensate for these limitations by creating new ways for preservice teachers to make connections between coursework and actual practices.

Emerging research from the first-wave of the COVID-19 pandemic reveals that teacher preparation programs have adjusted to replace field placements in several ways (Kim, 2020). A NAEYC report on the impact of COVID on ECE higher education programs reported that the most common strategy was replacing field experiences with videos and reflections (87\%) and approximately half of programs reported having students implement lessons with children they have access to, recording lessons, or implementing lessons virtually (Peyton et al., 2020). In the same study, very few programs $(6 \%)$ reported using simulation software to supplement field placements. However, mixed-reality simulations (e.g., Mursion ${ }^{\circledR}$, TeachLivE ${ }^{\mathrm{TM}}$ ) are a promising method for supporting the development of preservice teaching skills when field placements are limited by the pandemic
(Lee \& Freas, 2020). Simulations provide opportunities for students to engage in virtual environments that mimic the processes of actual field placements. A final strategy for replacing field placements identified in the literature is creating hypothetical scenarios for students to analyze and connect to course content. One way to do this is through videos or case studies that students respond to by planning appropriate lessons (Mollenkopf \& Gaskill, 2020). For example, teacher preparation programs have used high quality videos from Colorín Colorado (Grissom, 2020) and the Results Matter Video Library (Mollenkopf \& Gaskill, 2020) to identify teaching practices in action. Our ECE program created videos of our Child Development Lab School that was allowing children to attend face-to-face during the Fall of 2020 to support instruction of preservice teachers as well.

Through engagement in field placements, another key element of ECE teacher preparation programs influenced by COVID-19 is preservice teacher assessments, particularly those tied to field placements (Cutri et al., 2020; Peyton et al., 2020). As students engage in guided practice, formative assessments by instructors offer opportunities for professional growth (Hollins, 2011). Beyond this, more formalized student portfolios and performance based assessments document student professional growth and mastery of standards throughout teacher preparation programs (Foster et al., 2007). Student reflection on these performances leads to deeper understanding and internalization of standards. Additionally, ongoing assessments are also an integral piece of licensure and program accreditation.

Several factors have been identified in the literature that are related to a smoother transition to online learning in teacher education programs during the COVID-19 pandemic. Institutional supports, such as access to Learning Management Software, resources for moving courses online, and ongoing professional development can ease the transition (Quezada et al., 2020). Instructors' technological ability and online teaching experience also contribute to a smoother transition. Instructors with a greater understanding of online teaching strategies can better adjust the methods used to meet course learning outcomes. More nuanced attributes of instructors also play an important role in the transition to online learning. Cutri et al. (2020) found that willingness to try new things, confidence to be flexible and creative, and willingness to revise and adapt teaching practices all play an important role in the move to online learning for teacher educators.

As our program shifted teaching and field experiences in response to the pandemic, we sought to leverage existing resources and supports to uphold the social constructivist approaches and accreditation standards that are core to our teacher preparation program. Principles of social constructivism and postfoundationalism guide our approaches in transforming our coursework in response to the COVID-19 
pandemic. Social constructivism reinforces the idea that learning is socially constructed, in relation with others; knowledge is co-constructed (Vygotsky, 1978; Moss, 2019). Constructivist perspectives are being utilized in online learning (Green \& Johnson-Whitt, 2020; Flynn, 2020; Cherner, 2020) which helps students to focus on the process of their learning and the products they produce (Carwile, 2007). In this case, the reflective process of their learning and preparedness to teach and the lessons they taught as the product. Postfoundationalist perspectives hold that there is no universal truth and that there are many ways of knowing and being (Moss, 2019). This holds true for our context of multiple, shifting field placement types, acknowledging that students would have opportunities to demonstrate knowledge in many different ways that honored their personal experiences and their developing understanding of teaching and learning. One of these ways was through new modalities including online spaces, navigating new technologies, and developing meaningful interactions in these spaces. However, our COVID-19 context was unique in the fact that online, virtual spaces were part of our students' learning experiences and they all engaged in face-to-face learning or teaching spaces. In this way students were socially constructing in these faceto-face spaces and then bringing those relationships and conceptualizations to their online, virtual experiences.

We considered the voice of Loris Malaguzzi, father of the Reggio approach to guide our conceptualizations around responsiveness, "what children learn does not follow as an automatic result from what is taught, rather, it is in large part due to the children's own doing, as a consequence of their activities and our resources" (Wurm, 2005, p. 64). Malaguzzi reminds us of the context-specific nature of learning, reinforcing the notion that learning is an interactive process, heavily informed by our experiences. As we conceptualized and reconceptualized what it meant to "do" field placement during the pandemic, we regularly reflected on the state of our courses and experiences and used this to guide decision making in a responsive and receptive manner. We acknowledged that students were learning through their experiences, often vastly different from one another due to the pandemic, and that co-construction of their learning was dependent on collaboration with cooperating teachers, families, children, and course instructors, whether they were co-constructing virtually or otherwise.

\section{Context and Purpose of the Study}

We, two early childhood assistant professors, both new to our positions this year, sought to more deeply understand the professional standards and proficiency markers for our program while adapting coursework to support students' performance-based assessments in fieldwork-based courses.

Our large, public, South Central university maintained face-to-face courses in Fall 2020, through hyflex models allowing students the ability to attend class face-to-face or through Zoom. Faculty with documented accommodations for potential medical conditions that could make them more likely to get severely ill from COVID-19 were able to teach online. One of us taught in the hyflex model, and another in a synchronous online model. Flexibility was key in our response to instructional delivery and student assessment. Students and instructors experienced multiple 14-day quarantines due to exposure or infection. Students were engaged in a variety of field placements (Table 1) due to local guidelines set by various school districts. While we recognize that some of the modalities are not true "field placement", this is what they will be referred to throughout the paper.

Face-to-face field placements were traditional experiences with students placed in local classrooms with young children and cooperating teachers. Due to differing policies among school districts, students' experiences were very different. Some districts required masking and social distancing for teachers and students, while students placed in another public school were not required to maintain distance from students. In one course, students experienced two field placements after the first school changed their COVID policy a month after students had begun. Most face-to-face placements restricted the types of lessons that could be implemented in the classrooms.

Virtual field experiences were those conducted online with children in their virtual "classrooms" or virtually with young children in their homes with families. In the virtual classrooms (often delivered via Zoom or Google Meet), students engaged with children and cooperating teachers from a public school online. In the virtual experiences with young children in their homes, students

Table 1 Field placement types and their definitions

\begin{tabular}{ll}
\hline Field placement type & Definition \\
\hline Face-to-face & In-person, in an early childhood classroom with children and cooperating teacher present \\
Virtual & Online, in an early childhood "classroom" or with young children and their families at home \\
Hypothetical & Online, role-play based with students acting as children or the teacher as necessary \\
Mixed reality & Online, with an avatar and a live interactor (our students) \\
\hline
\end{tabular}


engaged families with infants and toddlers to learn about their families and provide relevant provocations-learning experiences designed to promote independent exploration and discovery based on children's interests and developmental levels - to engage the children with virtually. This led to collaboration between families and students to support children's interests, strengths, and needs in a responsive manner. Students either chose families with infants and toddlers who they had prior relationships, or they were placed with a volunteer family.

Hypothetical field placements were online, role-play based experiences with students acting as children or the teacher as necessary. Because students in one course were not allowed to implement the lessons, they designed with the children in their face-to-face field placement, they instead taught the lessons for one another. The instructor and other students acted as children for the lesson while they practiced teaching. Each person took turns and after the lesson received feedback from the instructor and their peers while also self-assessing their teaching.

Two courses engaged in mixed reality experiences as a field placement. Instructors chose scenarios that helped students engage in challenging situations that they might not be able to practice in a traditional field placement. Mixed reality also suspends disbelief (Hughes et al., 2005), making it more effective and engaging than traditional role play (Spencer et al., 2019). Mixed reality experiences allow students to interact with avatar children, family members, or other teachers. These avatars are responsive in both physicality (crossing arms and nodding heads) and discussion (direct responses to students' questions and comments). In a social studies course, students engaged in a mixed reality welcome lesson where they supported and engaged a dual language learner. In a family and community engagement course, students engaged in a mixed reality parent/teacher conference to address bullying happening in the classroom. Students tag-team during the scenario, passing turns with one student beginning the interaction, and another student picking up where the last one left off. This supports a collaborative, socially engaged, and constructivist approach to their teaching and learning through the experience.

COVID-19 policies and recommendations were in place by the university and the Professional Education Unit. All campus community members are asked to do a health selfscreening every morning before arriving on campus and wear masks inside campus buildings. University classrooms had socially distanced seating arrangements with seating charts and zero contact (e.g., no handouts or shared materials). Students on-campus and in field placements were required to wear masks regardless of local school district policy and were limited in the types of interactions and assignments allowed in classrooms.
Students are responsible for developing a portfolio during their study in the program demonstrating their mastery of Interstate Teacher Assessment and Support Consortium (InTASC) Model Core Teaching Standards (Council of Chief State School Officers, 2013) and Core Values of the Professional Education Unit at the university. In the student reflections later discussed in this article, InTASC standards are used to maintain consistency with program expectations and to support students' development in preparing portfolio materials.

The following research questions guided this study:

1. In what ways did early childhood teacher educators adapt teaching practices and performance-based assessments in response to the COVID-19 pandemic?

2. How did students and instructors perceive student learning and preparedness to teach based on the field placement adaptations provided to them?

\section{Method}

\section{Research Design}

This study engaged a retrospective mixed-method approach. All data were collected from previously graded course assignments and instructor ratings of course learning outcomes through students' lesson plans, evaluations of implementation videos, and fieldwork-based assignment reflections. All assignments were listed in course syllabi and were course requirements prior to the development of this research project. Because analyses occurred after all grading for the semester was complete and work was completely de-identified, our Institutional Review Board approved the study as exempt without individual informed consent. We used both quantitative and qualitative methods because assignments produced both numeric assessment and descriptive reflections.

\section{Participants}

The participants in this study were drawn from three cohorts of undergraduate preservice teachers in an Early Childhood Education program that results in state teacher certification at a large, public South Central university. This is a 4-year degree program, with the professional education program consisting of three semesters of coursework and a final semester of student teaching. Our study included only students in three cohorts of coursework and field placements prior to student teaching because the goals and expectations during student teaching differ significantly from those during pre-student teaching field experiences. The total sample across the three cohorts was 26 students. All participants 
were female with an average age of 21.65 years. Eighteen of the students were white $(69 \%)$ and all others were Latina, American Indian or Alaska Native, or Biracial. Students were $27 \%$ first-generation college students, and $85 \%$ of students were considered in-state residents. Three students either left the program during the semester or did not complete all relevant coursework.

\section{Instrumentation and Analysis}

Instructors assessed students' preparedness to teach, based on course learning outcomes, using relevant assignments across three stages of teaching (preparation, implementation, and reflection). Performance was rated using a four-point scale with the following anchors: (1) unacceptable, demonstrates competency in a fragmented manner or not at all; (2) approaches, demonstrates competency and would benefit from assistance or more experience; (3) meets, demonstrates competency effectively; and (4) exceeds, demonstrates competency seamlessly and effectively. This rating scale is consistent with the candidate evaluation used by supervisors in field placements. In some cases, students had multiple assignments for each of the three stages of teaching across the semester. Results will be reported for assignments overall and across students when possible. All quantitative data were analyzed using SPSS 26.

Reflections written after completing performance-based fieldwork assessment were the focus of qualitative data analysis. These reflections asked students to consider two elements: (1) of the 10 InTASC teaching standards, which standards did they feel that they met by completing the assignment and in what way they met it, and (2) based upon their initial reflection on standards, did they feel prepared/ not prepared to teach and why.

A qualitative-dominant approach was taken in this study due to the nature of student reflection and connections across field experiences. Working from a basis of grounded theory (Corbin \& Strauss, 1990), a constant comparative method was used to analyze across courses and assignments. Categories were established for each of the two elements by engaging in an open coding and axial coding process (Saldaña, 2013). While the reflection assignments were highly structured, initial and descriptive coding strategies (Saldaña, 2013) were employed to engage the constructivist nature of interpreting meaning across courses, remaining open to the possibilities of codes that might not have been established by the researcher on her own. Codebooks were established for each type of field placement and mapped by course. These were then cross-analyzed to determine themes across field placements and courses. One researcher with qualitative expertise established the codebooks and developed initial codes. Both researchers consulted on codes and emerging themes. We found this to be an appropriate method of inter-rater reliability, as each instructor was more familiar with the course expectations and overall experiences in their courses. All themes presented in this paper were agreed on by both researchers.

\section{Results}

The following results address research question one: in what ways did early childhood teacher educators adapt teaching practices and performance-based assessments in response to the COVID-19 pandemic?

Our response to developing curriculum that provided students opportunities to practice and apply knowledge gained in their courses was ever-evolving. As circumstances changed throughout the term, so did our responses. Students who regularly engaged in face-to-face field placement adapted to a variety of circumstances including face-to-face, virtual, hypothetical, and mixed reality (Table 2). Absent of COVID-19, field placements would have looked very different (Table 2). Students who maintained a face-to-face field placement for some or all of the semester were assigned these placements by the program Fieldwork Coordinator. Other fieldwork-based experiences were designed by instructors in response to limited/no fieldwork availability.

Assignments and assessments were designed to be flexibly implemented in our courses while still meeting course learning outcomes and standards. We used the plan-implement-reflect cycle to shape all of our fieldwork-based experiences for students to ensure that they would be getting consistent practice in this cyclical nature of teaching regardless of field placement type. We leveraged institutional resources, such as access to mixed-reality software, to increase opportunities for students. We also remained flexible to adapt to changing circumstances throughout the semester. For example, one student planned and reflected on a lesson but could not implement it due to illness. In another course, a student quickly revised a lesson and virtually implemented it with the instructor's child when the original plan was disrupted by the pandemic.

The following results address research question two: how did students and instructors perceive student learning and preparedness to teach based on the field experience adaptations provided to them?

\section{Student Learning Outcomes}

Instructor ratings of student learning across the three stages of teaching are reported in Fig. 1. Examining across three types of assignments, $61 \%$ of preparation assignments were rated meets or exceeds, $62 \%$ for implementation, and $67 \%$ for reflection. However, when examining across students, ratings of met or higher for at least one assignment for 
Table 2 Typical course field placements and COVID-19 adaptations by course

\begin{tabular}{|c|c|c|}
\hline Course & Typical placement type & COVID-19 placement adaptations \\
\hline Course \#1 & $\begin{array}{l}1 \text { half-day per week in the university child development lab with } \\
1-3 \text {-year-olds } \\
\text { Implementation of lessons from content-related courses }\end{array}$ & $\begin{array}{l}\text { Virtual placement with families who have a child birth-3-years- } \\
\text { old, via zoom that students knew or had access to. Students } \\
\text { without connections were offered a placement with a family. } \\
\text { Last-minute access to the instructor's toddler in one circum- } \\
\text { stance } \\
\text { Face-to-face placements with families who have a child birth-3- } \\
\text { years-old by choice instead of virtual placement }\end{array}$ \\
\hline Course \#2 & $\begin{array}{l}1 \text { full day per week in community PK-3rd grade classroom in } \\
\text { urban, suburban, or rural area } \\
\text { Implementation of lessons from content-related courses }\end{array}$ & $\begin{array}{l}\text { Face-to-face placements in } 2 \text { school districts, } 4 \text { weeks each due } \\
\text { to dismissal from the first site due to COVID-19 concerns. No } \\
\text { ability to implement curriculum } \\
\text { Hypothetical, role-play based curriculum implementation with } \\
\text { peers } \\
\text { Mixed reality lesson implementation for a small group of children } \\
\text { in a tag-team context to support a dual language learner/wel- } \\
\text { come lesson }\end{array}$ \\
\hline Course \#3 & $\begin{array}{l}2 \text { Full days per week in community PK-3rd grade classroom in } \\
\text { urban, suburban, or rural area } \\
\text { Implementation of 1-week curriculum unit }\end{array}$ & $\begin{array}{l}\text { Face-to-face placements } 1 \text { day per week in community and/or } \\
\text { virtual placements } \\
\text { Lesson implementation limited to requirements for task submis- } \\
\text { sion for state certification } \\
\text { Mixed reality parent/teacher conference in a tag-team context to } \\
\text { address the issue of the child being bullied in the classroom }\end{array}$ \\
\hline
\end{tabular}

Fig. 1 Instructor ratings of student learning outcomes

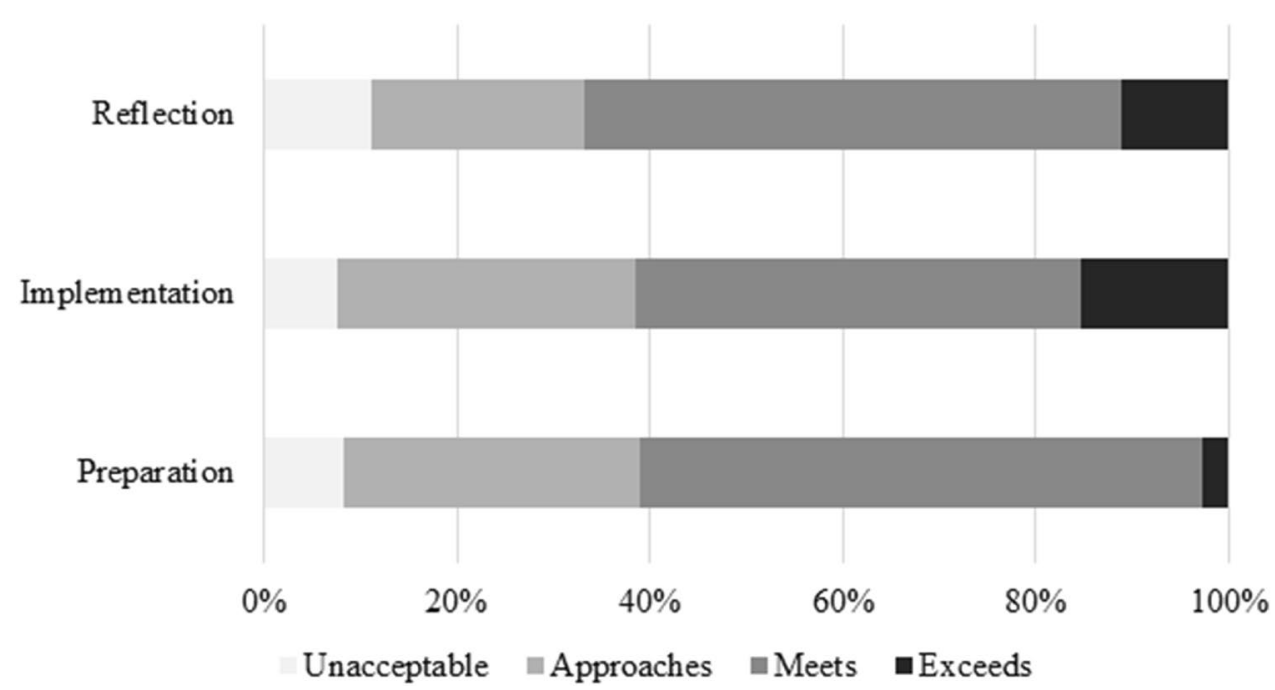

preparation were $65 \%, 61 \%$ for implementation, and $78 \%$ for reflection.

\section{Standards}

Student perception of learning was assessed by reflection on which standards they met in their lesson planning and implementation. All standards were mentioned by students at least once. Students reported a total of 161 standards across 36 reflections. The standard that students reported meeting the least was Standard 6: assessment $(n=9)$, and the standard that students reported meeting most was Standard 2: learning differences $(n=22)$. The percentage of students reporting each standard by field placement type are reported in Fig. 2.
The following categories were established by analyzing student responses to the question of which InTASC standards they met and how they met them. Each category is representative of responses from all three cohorts.

\section{Knowledge of Development}

Students reported that they possessed knowledge and skills regarding the developmental appropriateness of their curriculum design and the ways that this intersected with their developing understanding of connected concepts, such as play-based learning, schema development, and planning relevant instruction using developmental knowledge as a foundation. 


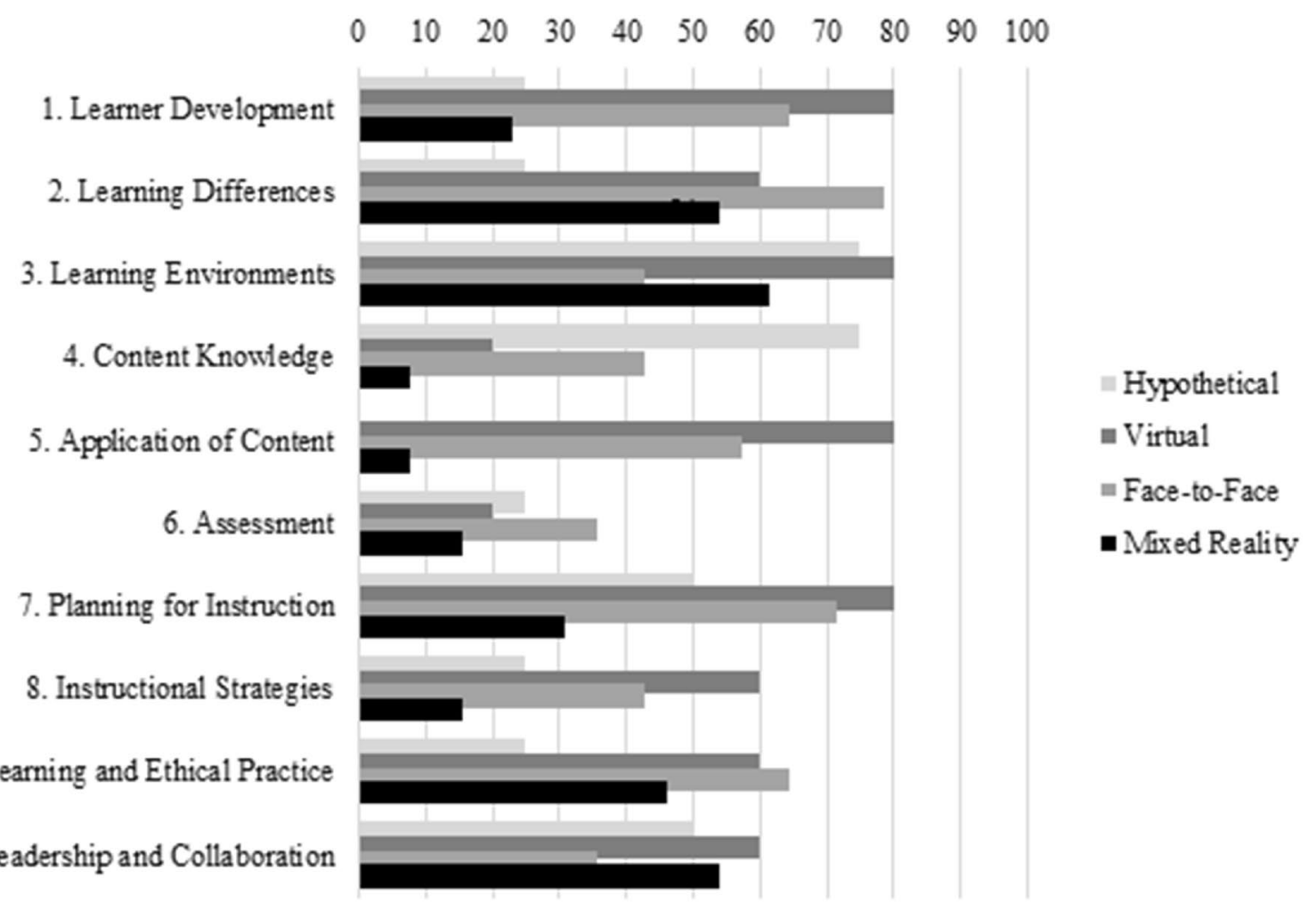

Fig. 2 Percentage of students reporting InTASC Standard by field placement type

One student (course \#1, standard 1, face-to-face) weaved the elements of using developmental knowledge to design curriculum by describing:

Starting with the family interviews, I learned about the child's interests and abilities from the parents and then based my provocation plan on those interests and abilities. I created and implemented a developmentally appropriate provocation based on what I learned from the interviews and understanding what exactly the child needed to be successful in this experience. I challenged her to use her imagination and creativity to build and create whatever she desired with the given material which I chose based on her interests and developmental level.

This developmental knowledge was informed by discussions of culture and family histories and experiences that provided students with a robust framework for conceptualizing development for young children.

\section{Relevant and Responsive Curriculum}

Several elements were described by students that relate to the concept of relevant and responsive curriculum, something that is multifaceted and inclusive of their developing teaching practices. Students noted their ability to engage in a variety of instructional strategies to meet the needs of all children, including those with exceptionalities and dual language learners. Students also cited the importance of planning curriculum that is responsive to drawing on existing knowledges of children and families as well as children's interests and abilities. Another student (course \#2, standard 7 , mixed reality) reflected on her rationale for planning for instruction:

I personally planned my instruction based on the fact that not everyone spoke the same language. So, when doing this, I wanted to draw on the knowledge of them having a different community context and plan so that everyone was included.

This planning is reflective of the student's responsiveness to children's abilities and how that informed her building an inclusive classroom space for all of her learners. Another student (course \#3, standard 6, face-to-face) addressed the nature of formative assessments informing responsive curriculum:

I used drawing and discussion as a means of assessment. I decided to use both because I know that some students have strengths in showing you what they know while other students are better at telling you what they know. I engaged learners in their growth 
by opening the floor to let them discuss and draw about their own lived experiences, and through this, I was able to monitor their progress. I also could use what I learned from this assignment for future lesson plans.

This reflection on assessment as it informs curriculum design employs a planning cycle inclusive of observation, implementation, and assessment.

\section{Collaborative Engagement}

Even though pandemic circumstances necessitated distancing, students found themselves engaged in collaboration and communication in many different circumstances. This engagement is reflective of their experiences working with classroom teachers, families, children, peers, and instructors throughout the semester. For some students, collaboration was evident in their planning and discussing children's growth and home experiences with families to design curriculum. Other students found their collaboration skills being developed among teachers through the tag-team model of mixed reality experiences. One student (course \#3, standard 3, mixed reality) reflected on her development of family engagement and collaboration in a mixed reality experience:

The simulation allowed me to meet with a parent and address issues going on at school with their child. I had the opportunity to discuss how we could make school a more positive environment for the child and help them become self-motivated. We discussed possible actions that could be taken and what needed to change in order for the student to feel safe in the school environment. The parent and I collaborated to find a common goal and possible next steps to create a safe and positive environment.

Another student (course \#1, standard 10, in-person) described the collaborative nature of using a family's expertise to design curriculum:

I collaborated with the family and [the child's] nanny to get the best idea of how to create an appropriate provocation to implement with [the child]. Interviewing the family helped to include them in what was going to be done and reflected leadership and collaboration throughout the whole process. Working with the family also helped, because they are the ones that know her the best, so it gave me the best ideas of what to include in my provocation.

This process is reflective of students' continued leadership in building relationships with the many stakeholders they will engage with in their role as teachers.

\section{Cultural and Familial Knowledge}

Students described the importance of culture and how it informs their teaching in diverse communities as well as the funds of knowledge (Moll et al., 1992) that children and their families possess. Even students who had not been introduced to the specific construct of funds of knowledge still described their understanding of family backgrounds and histories in a way that is respectful of multiple ways of knowing and being. One student (course \#2, standard 2 , mixed reality), meeting a new child in her mixed reality classroom acknowledged her cultural competence:

I asked our new student how to pronounce their name and that is an individual difference and I also went around the table and we spoke about our families and some of those looked different. Some students did not have siblings, some had many, some had a mom and dad, some had two dads. Everyone was included in my class discussion and all of their stories and opinions they brought to the table were valued and respected.

Another student (course \#3, standard 4, face-to-face) specifically designed curriculum centering children's funds of knowledge on transportation. She used a storied approach to learn more about their knowledge of transportation by engaging them in a lesson asking them to share experiences about places they have been. She reflected:

Because I did this lesson after I had done a lesson about rural and urban communities, I knew the content matter my students had mastered about transportation in both communities. I used this lesson as more of a reflection for students and to give them the opportunity to relate this lesson to their own lives. I know that students learn best when they are learning about what interests them and related to their own lived experiences.

This level of responsiveness to creating a design that allows children's interpretations and opportunities to share their knowledge and experience from their personal lives engages a funds of knowledge approach.

\section{Inclusive and Individualized Design}

Creating inclusive and individualized experiences for children was discussed through developmental and cultural lenses and the planning that resulted from this intentional perspective-taking. Students focused on how they could support all learners in their classrooms and the individual needs of each child. A student (course \#1, standard 5, virtual) discussed the planning that took place to think like a toddler to design effective and relevant curriculum: 
This was done because when I was brainstorming about the provocation plan, I was using not only my perspective on how I would interact with the objects I was given but I also tried to think about it from the perspective of a toddler and what would interest her.

Students also considered the instructional strategies they employed to ensure that all learners' needs would be met when interacting with a lesson. One student (course \#2, standard 8, hypothetical) discussed:

I believe I used many learning strategies to help students understand the content and build knowledge. For example, I used a video at the beginning of the lesson as an interactive tool to get students interested in the lesson. I then used discussions, group activities, and a Venn diagram to help my students understand the content and expand their knowledge.

Through intentional planning for inclusive and individualized experiences, students built their capacity for the application of relevant teaching strategies across field-placement types.

\section{Flexibility and Adaptability}

Lastly, students demonstrated and discussed the importance of being flexible and adaptable. This proves to be an important lesson for all teachers and has been magnified by the pandemic. Students reflected on needing to prepare for the unexpected and adapting things as they went. One student (course \#3, standard 9, face-to-face) identified the in-themoment experience of needing to make changes to planning:

When I prepped my lesson, I thought I had planned for the students and their needs pretty well. However, as I implemented the lesson with each group, I needed to adapt a part of my lesson for my students even more. I had to quickly adapt to help them complete the writing portion of the lesson because they needed help remembering how to spell some of the words. I evaluated my practices after that and realized that in the future I would need to prepare to help students a little bit more than I thought.

Students acknowledged the nature of working with children and that plans must often change as children interpret our designed experiences. One student (course \#1, standard 2, virtual) discussed:

Throughout the provocation plan, I learned that children do things differently than you have planned. This helps me understand the differences of each child and maybe how I could create the best experience to keep them involved.
Remaining flexible and adaptable are crucial skills in teaching and learning contexts, something which preservice teachers need to practice in order to become successful in their classrooms.

\section{Preparedness to Teach}

For most students, asking them if they felt prepared or not prepared to teach based on the fieldwork-based assignment they had completed, led to a discussion of feeling both prepared to do some things and not prepared to do others. Only two students indicated on one assignment that they felt entirely prepared and one student indicated on one assignment that they did not feel prepared at all.

\section{Prepared}

Students demonstrated preparedness through several areas but were specifically related to the cyclical nature of planning including curriculum development, implementation, and reflective practice.

Curriculum Design Students described many ways that they felt prepared to teach that informs their ability to develop curriculum and plan effectively. Students cited knowledge and use of state and national standards and the ways they were able to make connections between experiences for children and these measures of learning. Planning and preparing in-depth before implementing served students in helping them to use context-specific information to inform their preparation, research, and design of curriculum. One student (course \#2, hypothetical) described how planning helped her feel prepared:

I feel like my lesson plan made me more prepared. It made me think of the "why" when planning. Even though I believe I could have done better with it, it still made me excited to get better at it.

Implementation While implementation of curriculum experiences looked significantly different this semester, students found value in their experiences. One important aspect of implementing curriculum included being flexible, adaptable, and able to improvise. Students also felt prepared and confident implementing engaging activities. One student (course \#3, mixed reality) discussed the benefits of preparing for and having a family conference with an avatar:

I think this is helpful to understand that you really need to be prepared for anything the parent might say. It's also just good practice since a lot of education majors will have very little prior experience working with parents. 
This acknowledges that some skills, like meeting with families regarding challenges in the classroom, are helpful to engage in through mixed reality because students in traditional fieldwork placements rarely have these opportunities to practice.

Reflective Practice The reflections on whether students felt prepared to teach or not naturally engaged them in a process of reflective practice. Students reported some specific examples that contribute to their reflections on their teaching and their growth as professionals. Some students engaged deeply with their newly acquired knowledge. One student (course \#2, hypothetical) developed curriculum around citizenship and what it meant to be a good citizen. She reflected:

I felt that I relied too much solely on whether the students [knew] rules or had good citizenship skills. I wondered what if the kids don't hold the door open or don't take their shoes off before they come in the house. I feel like I need to work on my assumptions [about whether] they have the same morals and culture as myself. If they don't, then I need to change the way I implement the lesson... so they can still master that standard but learn in their own way.

While this reflection acknowledged some of the things the student was not prepared to do, it also indicates an actionable step toward acknowledging changes that must be made intentionally.

\section{Not Prepared}

Students found themselves un/underprepared for a variety of elements in teaching. These were overwhelmingly related to needing more practice in the field and developing stronger skills to be able to teach.

Need Practice Students described their need for practice for many elements of teaching including support with groups/ multiple children at once and strategies for supporting diverse groups of children and learning needs. Some students were concerned about not fully understanding how to teach what they had prepared or how to teach an "actual lesson" that was "content" based. One student (course \#1, virtual) reflected specifically on the need to have time in classrooms to engage in learning:

One reason I do not feel prepared to teach is because my block in ECE has been shorted observation hours in the [lab school], as well as at [community agency]. I feel like we are lacking valuable hours of observing teachers and being in an Infant and Toddler classroom. I wish Covid-19 was not a thing that way we could have been able to have those observation hours in the classroom.

Even with modified assignments that allowed for some experience, this sentiment reflects students' desire to be in classrooms regularly observing and practicing what they have learned in class.

Need Skills Development Students cited specific skills as lacking that they need to teach effectively. However, these skills were all over the map with students describing content-based issues like guidance strategies, literacy development, dual language learner support, differentiation, implementing standards, etc. Students also identified skills that are more nuanced such as collaboration with colleagues, creative ways to implement ideas, making sure all children understand the material, teaching all day, and teaching online.

\section{Discussion}

Together, these findings provide a broad understanding of how adaptations to coursework amidst the COVID-19 pandemic supported preservice teachers in developing knowledge and skills across courses. Students discussed the skills they needed to feel prepared to teach that they felt they were lacking. This assessment of their learning indicated two major issues. First, some skills students cited are ones that are grown over time and with practice. Because of this, we know that there will be time and experiences provided throughout their study to develop these (Feiman-Nemser, 2001). Second, analysis of standards met across placement types highlights areas of need across courses and the program as a whole. Of the InTASC standards students reflected on, assessment was the lowest $(n=9)$ and learning differences $(n=22)$ being the highest. While summative assessments may have been challenging to make during these coursework modifications, it is a reminder to stress the importance of formative assessment (Menéndez et al., 2019), something that we saw many students engage with successfully. Students did practice skills in individualization and differentiation and some of them encountered scenarios where they focused on inclusion of diverse learners. One student remarked:

Before this, I never thought much about how hard it will be to make sure everyone feels comfortable and welcomed in my class, no matter their culture or language. So I feel more prepared to be prepared in my future classroom. I now know that there are ways to help and there are resources to help. 
Engaging with learning differences and embodying an equity mindset is something to which both of us, as instructors, are committed in our pedagogy. Students may be familiarizing themselves with diverse populations for the first time and this exposure may have contributed to such a high rating of learning differences.

While some students did not meet expectations for fieldwork-based assignments, often their reflections demonstrated that they are learning, reflecting, and applying new knowledge. In the reflection of InTASC standards, students across three courses and four different instructional modalities found application of skills and knowledge that met all 10 InTASC standards. Even though this is across a sample of 23 students, it is encouraging to see the interdisciplinarity of course assignments and the learning that can be accomplished by using a variety of fieldwork-based experiences. In some cases, students were able to master concepts in one assignment that they found difficult in a previous assignment. In other cases, students identified very different standards across assignments for the same class.

\section{Unintended Benefits}

There were also several unintended benefits of coursework adaptations made during our semester. Students were able to participate in mixed reality experiences for the first time in our program. One of us had experience using mixed reality and a prior institution and the other reached out to see if our students could use the technology to support our fieldworkbased experiences. Mixed reality is an important practice that helps students navigate challenging conversations and scenarios (Spencer et al., 2019). Using mixed reality is not only useful during a pandemic, but instead of acting as a supplement, became a major aspect of course learning due to lack of face-to-face experiences.

Another benefit was the development of stronger relationships with families and the collaborative and reciprocal nature of sharing with families. For students who helped design curriculum in collaboration with families by interviewing them regarding the child's development and cultural norms, they found opportunities for communication that would not have been possible in their typical center-based field placement with minimal family interaction. Because of assignments like this, students demonstrated cultural and family awareness that they applied in implementation and reflections.

Lastly, students were able to engage in a generative feedback process for one another. In one course, after students finished implementing a lesson on zoom with their peers everyone took time to provide detailed feedback, self-reflection, peer feedback, and instructor feedback and support. In a typical field placement, students might only receive feedback from the cooperating teacher and university supervisor.

\section{Implications for Teacher Preparation Programs}

As we reflect on our practice and the adaptations made to our courses, we return to principles of social constructivism and postfoundationalism. Our assessments of our students' learning and their assessments of their learning can co-exist. Because there is room for differing perspectives and multiple ways of knowing and being, we recognize that there is room for a multifaceted interpretation of learning, dependent on the individualized contexts for each learner (Moss, 2019). It seems, in a time when there are so many unknowns, that having flexibility and being adaptable with our courses is of best service to our students and ourselves. By taking this approach in our own coursework, the current study reveals our ability to accommodate individual learners through flexible assignments and divergent paths to course learning outcomes. We have discovered that the same principles of individualized and differentiated instruction that are expected in ECEC contexts (Tomlinson, 2014) are possible in university classrooms as well. This highlights that teacher preparation programs should work to maintain adaptable course delivery and assignment options beyond the COVID-19 pandemic because emergent and flexible practices honor the contexts we work in with young children. This flexibility and adaptability engages an equity mindset to student success and can be employed anytime there is an emergency or serious challenge in our classrooms.

Furthermore, while our goal for this research study was to assess learning based on new fieldwork-based placements to ensure students were meeting standards, it begs the question: aren't there more important things to be worrying about than standards right now? We recommend that instructors remain flexible and responsive to the ever-shifting landscape in teacher preparation as we continue to move through the pandemic. We consider the principles of social citizenship (Swadener et al., 2020) and what it could mean for people in our program to take care of themselves and their learning, but also to care for one another as we co-exist in our learning spaces. Our small program had three students leave in fall 2020, consistent with the $90 \%$ of teacher education programs that saw attrition during the pandemic (Peyton et al., 2020). Principles of care and social citizenship could be used to address issues of attrition in our programs, as we put relationships at the forefront of our work.

\section{Strengths and Limitations}

This study outlines course adaptations in response to the COVID-19 pandemic and evaluates self- and instructorassessment of student learning outcomes. Not only does this work contribute to the documentation of experiences of teacher preparation programs during the global pandemic, but it demonstrates the power of responsive practices by 
faculty and students' ability to construct knowledge of teaching practices across multiple modalities of field work. The use of mixed-methods contributes preliminary quantitative data on multiple modes of field work, while providing rich qualitative analysis of student reflection. While this work is based on adaptations during a global emergency, the findings contribute to our ever-evolving understanding of best practices in early childhood teacher education.

However, we must acknowledge several limitations. First, our sample had a relatively small and homogenous sample. A larger sample would allow for comparison across instructors and potentially across programs. While a small sample such as this intimately reflects the students' learning across our program, future studies could engage large scale survey research on teacher candidates' field experiences, offering a different type of data and insights. Second, the evaluation of lesson implementation was missing for a large portion of students because instructors were not allowed in the school or the lesson was implemented hypothetically. Better evaluation of this area of the plan, implement, reflect cycle could support student learning and our assessment of it. Finally, this study was conducted retrospectively, so we were only able to evaluate deidentified student assignments. Including measures of student stressors and pandemic impacts, wellbeing, adaptation, and resilience would have better contextualized these findings.

We return to the unintended benefits we saw happen in our learning environments this fall. These benefits have the potential to shape new ways of conceptualizing student learning, especially in field placements. As we move through this pandemic, we acknowledge that there is no returning to normal. There must be progress and intentional reflection on the spaces and experiences that have been created. Across teacher preparation contexts worldwide, experiences working with children have been required to shift, adapt, and be malleable. Early childhood teacher educators and early childhood educators have the ability to build anew. We invite you to wonder with us, How do early childhood teacher educators move forward aligning our values with the types of educational experiences we provide post-pandemic? What could it look like to build better in early childhood teacher preparation?

Acknowledgements We would like to thank Mary Taggart for summarizing program demographics.

\section{References}

Capraro, M.M., Capraro, R.M., \& Helfeldt, J. (2010). Do differing types of field experiences make a difference in teacher candidates' perceived level of competence? Teacher Education Quarterly, 37, 131-154. Retrieved from http://www.jstor.org/stable/23479302
Carillo, C., \& Flores, M. A. (2020). COVID-19 and teacher education: A literature review of online teaching and learning practices. European Journal of Teacher Education, 43, 466-487. https://doi.org/10.1080/02619768.2020.1821184

Carwile, J. (2007). A constructivist approach to online teaching and learning. Inquiry, 12, 68-73. Retrieved from https://eric.ed. gov/?id=EJ833907

Cherner, T. (2020). Take back social constructivism: A process for teacher educators to design collaborative, asynchronous learning experiences. In R.E. Ferdig, E. Baumgartner, R. Hartshorne, R. Kaplan-Rakowski, \& C. Mouza (Eds.), Teaching, technology, and teacher education during the COVID-19 pandemic: Stories from the field (pp. 479-482). https://www.learntechlib. org/p/216903/

Council of Chief State School Officers. (2013). InTASC model core teaching standards and learning progressions for teachers 1.0 . Retrieved from https://ccsso.org/sites/default/files/2017-12/ 2013_INTASC_Learning_Progressions_for_Teachers.pdf

Corbin, J. M., \& Strauss, A. (1990). Grounded theory research: Procedures, canons and evaluative criteria. Qualitative Sociology, 13, 3-21. https://doi.org/10.1007/BF00988593

Cutri, R. M., Mena, J., \& Whiting, E. F. (2020). Faculty readiness for online crisis teaching: Transitioning to online teaching during the COVID-19 pandemic. European Journal of Teacher Education, 43, 523-541. https://doi.org/10.1080/02619768.2020. 1815702

Dibner, K., Schweingruber, H., \& Christakis, D. (2020). Reopening K-12 schools during the COVID-19 pandemic: A report from the national academies of sciences, engineering, and medicine. Journal of American Medical Association, 324, 833-834. https://doi. org/10.1001/jama.2020.14745

Feiman-Nemser, S. (2001). From preparation to practice: Designing a continuum to strengthen and sustain teaching. Teachers College Record, 103, 1013-1055. Retrieved from https://eric.ed.gov/?id= EJ640144

Flynn, P. (2020). Enhancing K-12 pre-service teachers' digital pedagogy literacy: Lesson planning for teaching online. In R.E. Ferdig, E. Baumgartner, R. Hartshorne, R. Kaplan-Rakowski, \& C. Mouza (Eds.), Teaching, technology, and teacher education during the COVID-19 pandemic: Stories from the field (pp. 71-76). https://www.learntechlib.org/p/216903/

Foster, B., Walker, M., \& Song, K. (2007). A beginning teaching portfolio handbook: Documenting and reflecting on your professional growth and abilities. Pearson Education Inc.

Green, J. \& Johnson-Whitt, E. (2020). Through the constructivist lens: A vision for preparing pre-service teachers for online. In R.E. Ferdig, E. Baumgartner, R. Hartshorne, R. Kaplan-Rakowski, \& C. Mouza (Eds.), Teaching, technology, and teacher education during the COVID-19 pandemic: Stories from the field (pp. 379-386). https://www.learntechlib.org/p/216903/

Grissom, D. (2020). Experiential learning through video observations. In R.E. Ferdig, E. Baumgartner, R. Hartshorne, R. KaplanRakowski, \& C. Mouza (Eds.), Teaching, technology, and teacher education during the COVID-19 pandemic: Stories from the field (pp. 97-112). https://www.learntechlib.org/p/216903/

Kim, J. (2020). Learning and teaching online during Covid-19: Experiences of student teachers in an early childhood education practicum. International Journal of Early Childhood, 52, 145-158. https://doi.org/10.1007/s13158-020-00272-6

Lee, C.W. \& Freas, H. (2020). Utilizing teaching simulations for small group mathematics discussions in the void of field placement opportunities. In R.E. Ferdig, E. Baumgartner, R. Hartshorne, R. Kaplan-Rakowski, \& C. Mouza (Eds.), Teaching, technology, and teacher education during the COVID-19 pandemic: Stories from the field (pp. 335-341). https://www.learntechlib.org/p/216903/ 
Levinson, M., Cevik, M., \& Lipsitch, M. (2020). Reopening primary schools during the pandemic. The New England Journal of Medicine, 383, 981-985.

Menéndez, I. Y. C., Napa, M. A. C., Moreira, M. L. M., \& Zambrano, G. G. V. (2019). The importance of formative assessment in the learning teaching process. International Journal of Social Sciences and Humanities, 3, 238-249. https://doi.org/10.29332/ijssh. v3n2.322

Moll, L. C., Amanti, C., Neff, D., \& Gonzalez, N. (1992). Funds of knowledge for teaching: Using a qualitative approach to connect homes and classrooms. Theory into Practice, 31, 132-141. https:// doi.org/10.1080/0040584920954534

Mollenkopf, D. \& Gaskill, M. (2020). Creating meaningful learning experiences for pre-service and in-service teachers facing interruptions in field experience placements during the COVID-19 pandemic. In R.E. Ferdig, E. Baumgartner, R. Hartshorne, R. Kaplan-Rakowski, \& C. Mouza (Eds.), Teaching, technology, and teacher education during the COVID-19 pandemic: Stories from the field (pp. 347-354). https://www.learntechlib.org/p/216903/

Moore, R. (2003). Reexamining the field experiences of preservice teachers. Journal of Teacher Education, 54(1), 31-42. https://doi. org/10.1177/002248710223856

Moss, P. (2019). Alternative narratives in early childhood: An introduction for students and practitioners. Routledge.

Murray, J. (2020). In a time of COVID-19 and beyond, the world needs early childhood educators. Journal of Early Years Education, 28, 299-302. https://doi.org/10.1080/09669760.2020.1839830

Pacansky-Brock, M., Smedshammer, M., \& Vincent-Layton, K. (2020). Humanizing online teaching to equitize higher education. Current Issues in Education, 21(2), 1-21. http://cie.asu.edu/ojs/index.php/ cieatasu/article/view/1905

Peyton, J., Ehrenberg, P., Harrill, M., Hogan, L., \& Woolston, M. (2020). From on campus to online: The impact of the pandemic on ECE higher education programs. National Association for the Education of Young Children. https://www.naeyc.org/sites/defau lt/files/globally-shared/downloads/PDFs/resources/topics/covid_ higher_ed_brief.pdf

Quezada, R. L., Talbot, C., \& Quezada-Parker, K. B. (2020). From bricks and mortar to remote teaching: A teacher education program's response to COVID-19. Journal of Education for Teaching, 46, 472-483. https://doi.org/10.1080/02607476.2020.18013 30

Saldaña, J. (2013). The coding manual for qualitative researchers (2nd ed.). Sage.

Spencer, S., Drescher, T., Sears, J., \& Scruggs, A. F. (2019). Comparing the efficacy of virtual simulation to traditional role-play. Journal of Educational Computing Research, 57, 1772-1785. https:// doi.org/10.1177/0735633119855613

Swadener, B. B., Peters, L., Bentley, D. F., Diaz, X., \& Bloch, M. (2020). Child care and COVID: Precarious communities in distanced times. Global Studies of Childhood, 10, 313-326. https:// doi.org/10.1177/2043610620970552

Szente, J. (2020). Live virtual sessions with toddlers and preschoolers amid COVID-19: Implications for early childhood teacher education. Journal of Technology and Teacher Education, 28, 373-380.

Tomlinson, C. A. (2014). The differentiated classroom: Responding to the needs of all learners. ASCD.

Vygotsky, L. (1978). Mind in society. Harvard University Press.

Wurm, J. P. (2005). Working in the Reggio way: A beginner's guide for American teachers. Red Leaf Press.

Publisher's Note Springer Nature remains neutral with regard to jurisdictional claims in published maps and institutional affiliations. 